\title{
Recent Research and Development of Reduced Activation Ferrous Materials in Japan
}

\section{Yuzo HOSOI}

Department of Materials Science and Engineering, Faculty of Engineering, Nagoya University, Furo-cho, Chikusa-ku, Nagoya, Aichi-ken, 464 Japan.

(Received on May 7, 1990; accepted in the final form on June 29, 1990)

\begin{abstract}
The outline of research and development of reduced activation ferrous materials, today in Japan, is reviewed. Reduced activation ferrous materials are considered to be utilized for the first wall materials of fusion reactor. The concept of reduced activation materials is closely related to the waste management and reactor safety. The decay behavior of induced radioactivity shows that the substitution of $\mathrm{Mn}$ for $\mathrm{Ni}$ and that of $\mathrm{W}$ for $\mathrm{Mo}$ in ferrous materials are very effective to achieve a reduced level of long-term radioactivity. The efforts are being devoted to the development of ferritic $9 \mathrm{Cr}-\mathrm{W}$ steels, austenitic $\mathrm{Mn}-\mathrm{Cr}$ steels and $\mathrm{Mn}-\mathrm{Cr}-\mathrm{W}$ steels as candidate alloys, instead of $9 \mathrm{Cr}-\mathrm{Mo}$ steels and modified type 316 stainless steels. Some results are presented to the toughness before and after neutron irradiation and creep rupture strength of $9 \mathrm{Cr}-\mathrm{W}$ steels, and on the characterisitcs of sigma phase formation, high-temperature strength, and void swelling of austenitic $\mathrm{Mn}-\mathrm{Cr}$ steels and $\mathrm{Mn}-\mathrm{Cr}-\mathrm{W}$ steels. Preferable chemical compositions for reduced activation ferrous materials are suggested.
\end{abstract}

KEY WORDS: ferritic 9Cr-W steels; austenitic $\mathrm{Mn}-\mathrm{Cr}$ steels; induced radioactivity; toughness; high-temperature strength; sigma phase formation.

\section{Introduction}

The first wall materials of fusion reactor are strongly activated by neutrons with high energy of $14 \mathrm{MeV}$, produced by $\mathrm{D}-\mathrm{T}$ reaction. ${ }^{*}$ This induced radioactivity of the materials is considered to be one of the most serious problems from the view-points of reactor safety, operation and maintenance, waste management and environmental concerns for fusion reactor.

The research works of reduced activation materials originated in the early $1980 \mathrm{~s}$ in U.K. and U.S.A. The studies were mainly focused on the decay characteristics of the radioactive isotopes that make up typical structural materials. ${ }^{1)}$ The work on reduced activation materials is now extended to radiation damage, structural stability, mechanical properties and alloy design in U.S.A., Europe and Japan. ${ }^{1-6)}$

In Japan, the study of low or reduced activation materials had started about 5 years ago in Japan Atomic Energy Research Institute, National Research Institute for Metals, and University Collaborative Research Group under the leadership of A. Miyahara and S. Ishino by sponsorship of the Grant-in-Aid for Fusion Research of the Ministry of Education, Science and Culture of Japan.

The low or reduced activation materials are required from the contact maintenance, waste management, and reactor safety. Some goal of such items was pointed out as follows ${ }^{7}$ :
1) Contact maintenance-Surface dose rate or $\gamma$-ray attains $2.5 \mathrm{mrem} / \mathrm{h}$ within several weeks after shutdown.

2) Waste management-The activity satisfies the land disposal limits such as natural radioactivity level in 100 years after shutdown or 10GFR61 limits (Part 61 of Title 10 of US Code of Federal Regulations ${ }^{8)}$ ) with respected to land burial of radioactive waste.

3) Reactor safety-Minimum BHP (biological hazard potential) values or lowest decay heat.

As far as the contact maintenance, the selection of materials is very limited. U.S. Department of Energy Panel in 1983 suggested that high-purity silicon carbide was only true low activation material. ${ }^{1)}$ It is clearly understood from the decay characteristics of $\mathrm{Si}$ and $\mathrm{C}$ being referred from Fig. 1.7) Vanadium would be selected in this class. There are, however, several difficulties in producing and fabricating large constructional structure using these materials, and also in controlling the impurity concentration at a level of ppm or less. On the other hand, ferrous materials are the most suitable for the construction of large structure because of many examples of large structure in nuclear plants and numerous data of mechanical, physical, chemical properties, fabricability, weldability and so on. Accordingly, the development of reduced activation ferrous materials is the most practical way for the construction of first wall. In

\footnotetext{
* The first wall of fusion reactor is the inner wall of huge vacuum vessel facing the plasma where $\mathrm{D}$ (deuterium)- $\mathrm{T}$ (tritium) fusion reaction occurs; ${ }^{2} \mathrm{D}+{ }^{3} \mathrm{~T}={ }^{4} \mathrm{He}(3.52 \mathrm{MeV})+n(14.06 \mathrm{MeV})$.
} 


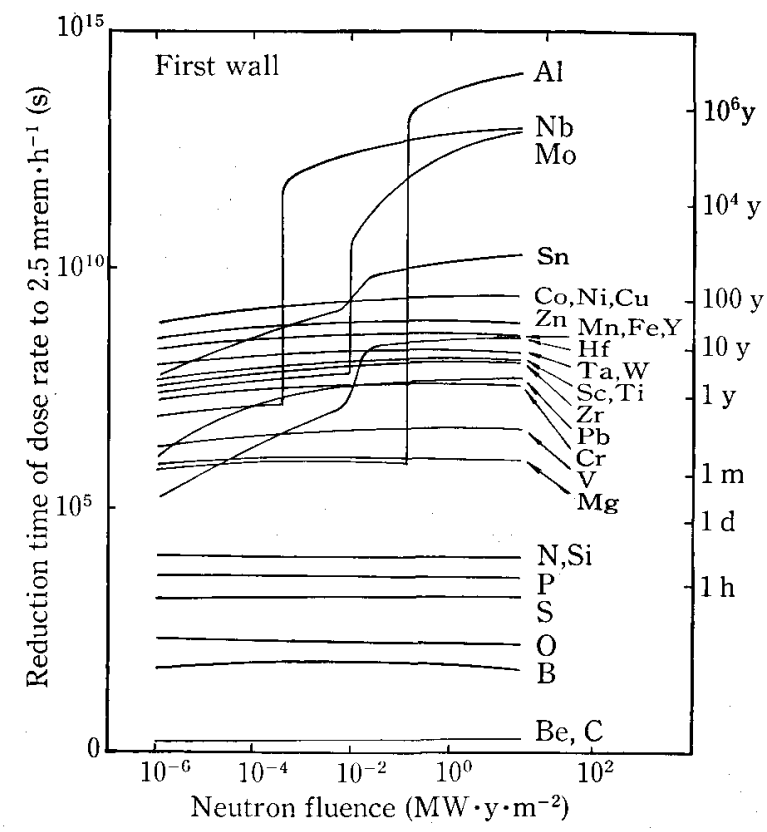

Fig. 1. The cooling time of first wall materials required for $2.5 \mathrm{mrem} \cdot \mathrm{h}^{-1}$ as a function of neutron fluence.

this sense, it is required to develop the reduced activation ferrous materials which satisfy the land disposal limit, 10CFR61 limit. The Panel mentioned above previously recommended also that materials be developed to help avoid a nuclear waste-disposal problem that would occur when fusion reactor components had to be discarded. ${ }^{11}$

This review gives an outline of the trend and research and development of reduced ferrous materials in Japan.

\section{Induced Radioactivity of Elements}

Induced radioactivity of elements has been calculated by several investigators. One of examples of calculation results of induced radioactivity of elements and their decay behaviors is shown in Fig. 1. This figure shows the cooling time for several elements required for $2.5 \mathrm{mrem} \cdot \mathrm{h}^{-1}$ as a function of the neutron fluence. $\mathrm{Si}$ and $\mathrm{C}$ show the very fast decay even after irradiation of the neutron fluence of $10 \mathrm{MW} \cdot \mathrm{y} \cdot$ $\mathrm{m}^{-2}$. Chromium requires about 1 year and $\mathrm{Fe}$ and $\mathrm{W}$ about 10 years for the cooling time, whereas $\mathrm{Ni}$ requires about 100 years after irradiation of similar level of neutron fluence. In the case of Mo, the cooling time increases steeply at around $10^{-2} \mathrm{MW} \cdot \mathrm{y} \cdot \mathrm{m}^{-2}$, because of the accumulation of long-lived nuclides such as ${ }^{94} \mathrm{Nb},{ }^{92} \mathrm{Nb}$ for Mo. ${ }^{7}$

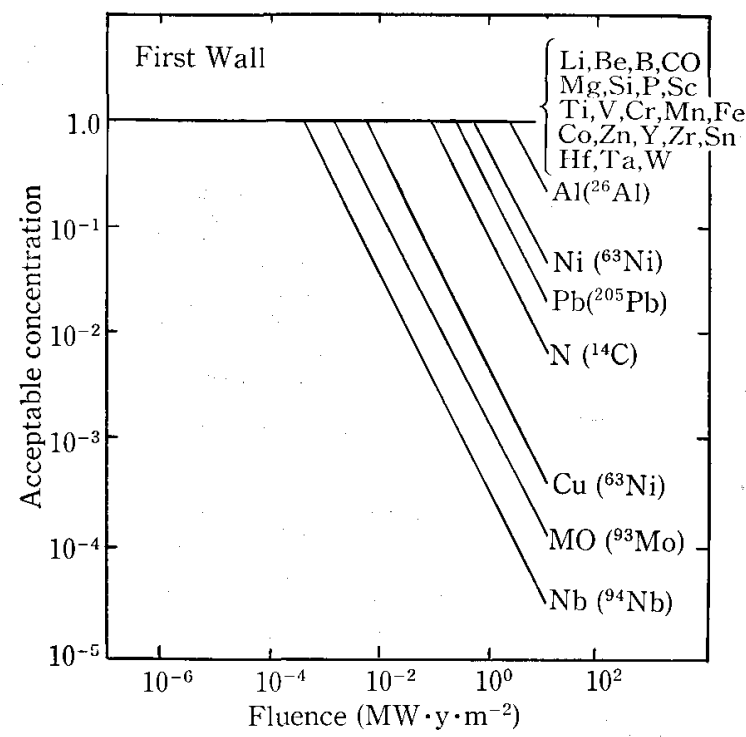

Fig. 2. Necessary concentration of first wall materials of which activities satisfy 10CFR61 class $\mathrm{C}$ limits just after shutdown as a function of nuetron fluence.

Fig. 2 shows the acceptable concentration of elements required to satisfy the class $\mathrm{C}$ limit of 10CFR61 as a function of the neutron fluence. ${ }^{7)}$ It is noted that $\mathrm{Fe}, \mathrm{Mn}, \mathrm{Gr}, \mathrm{V}, \mathrm{W}$ and $\mathrm{Ti}$ are not limited in concentration as first wall material to make class $\mathrm{C}$ limit disposal in the operation of $10 \mathrm{MW} \cdot \mathrm{y} \cdot \mathrm{m}^{-2}$. F. M. $\mathrm{Mann}^{9)}$ proposed the acceptable concentration of elements to make class $\mathrm{C}$ limit as follows; $\mathrm{Nb}<0.00029$ $\%, \mathrm{Mo}<0.003 \%, \mathrm{Cu}<0.12 \%, \mathrm{~N}<0.33 \%, \mathrm{Ni}<0.91$ $\%, \mathrm{~Pb}<3.1 \%$, and $\mathrm{Al}<3.6 \%$.

\section{Reduction of Radioactivity for Ferrous Materials}

Type 316 stainless steel and modified type 316 (PCA and JPCA)* have been considered to be preferable candidate alloys for the first wall material, because of balanced properties for structural material and numerous data of radiation damage. On the other hand, recently, ferritic heat resisting steels, modified 9 $\mathrm{Cr}-\mathrm{Mo}^{*}$ and HT9* steels, have also been selected as candidate materials from the standpoint of superior resistance to void swelling and helium embrittlement compared with austenitic alloys. ${ }^{10)}$

As mentioned above in previous section for radioactivity of elements, the substitution of $\mathrm{Mn}$ for $\mathrm{Ni}$ and that of $\mathrm{W}$ for Mo in ferrous materials are very effective to achieve a reduced level of long-term radioactivity, taking into consideration of role of alloying

\begin{tabular}{|c|c|c|c|c|c|c|c|c|c|c|c|c|}
\hline \multirow[t]{2}{*}{$*$} & \multicolumn{12}{|c|}{ Nominal chemical composition (mass\%) } \\
\hline & & $\mathrm{C}$ & $\mathrm{Si}$ & $\mathrm{Mn}$ & $\mathrm{Cr}$ & $\mathrm{Ni}$ & Mo & $\mathrm{Ti}$ & V & $\mathrm{Nb}$ & W & $\mathbf{P}$ \\
\hline & Type 316 & 0.05 & 0.5 & 1.5 & 18.0 & 12.0 & 2.3 & - & $\ldots$ & - & - & 0.02 \\
\hline & PCA & 0.05 & 0.4 & 1.8 & 14.0 & 16.0 & 2.3 & 0.24 & - & - & - & 0.01 \\
\hline & JPGA & 0.05 & 0.5 & 1.8 & 15.0 & 16.0 & 2.3 & 0.24 & - & - & - & 0.03 \\
\hline & Mod. 9Gr & 0.10 & 0.3 & 0.5 & 9.0 & - & 1.0 & - & 0.2 & 0.10 & - & - \\
\hline & НТ9 & 0.20 & 0.3 & 0.5 & 11.0 & 0.5 & 1.0 & - & 0.3 & 0.30 & 0.5 & 一 \\
\hline & JFMS & 0.05 & 0.7 & 0.5 & 10.0 & 0.9 & 2.3 & - & 0.1 & 0.06 & - & - \\
\hline
\end{tabular}


elements in the materials. It introduces that ferritic 9 to $12 \mathrm{Cr}-\mathrm{W}$ steels instead of 9 to $12 \mathrm{Gr}-\mathrm{Mo}$ steels (modified 9Cr-Mo, HT9, or JFMS)* and austenitic high $\mathrm{Mn}-\mathrm{Cr}$ and high $\mathrm{Mn}-\mathrm{Cr}-\mathrm{W}$ steels instead of $\mathrm{Ni}-\mathrm{Cr}$-Mo steels (AISI 316, PGA, or JPGA) are available as preferable candidates for reduced activation ferrous materials. Fig. 3 shows the decay of surface dose rate of induced activity of PGA, 9 Gr-2W steel and $30 \mathrm{Mn}-10 \mathrm{Cr}$ steel with cooling time. ${ }^{11)}$ The first gamma-ray intensity was estimated as the intensity after shutdown of operation of $1 \mathrm{MW} \cdot \mathrm{m}^{-2}$ for 10 years. It is obvious that the decay of induced activity of $9 \mathrm{Cr}-2 \mathrm{~W}$ and $30 \mathrm{Mn}-10 \mathrm{Cr}$ steels is much faster than that of PCA which contains Ni and Mo.

Under these conditions, the fundamental studies and the development of ferritic $\mathrm{Cr}-\mathrm{W}$ steels and austenitic Mn-Cr steels have been promoted as reduced activation ferrous materials for fusion reactor. The important theme to be studied in these materials are toughness, fracture toughness, high-temperature strength, compatibility to environment, and radiation damage for ferritic alloys, and structural stability at high-temperature, high-temperature strength, compatibility to environment and radiation damage for austenitic alloys. Weldability and formability are also investigated for the development of these materials.

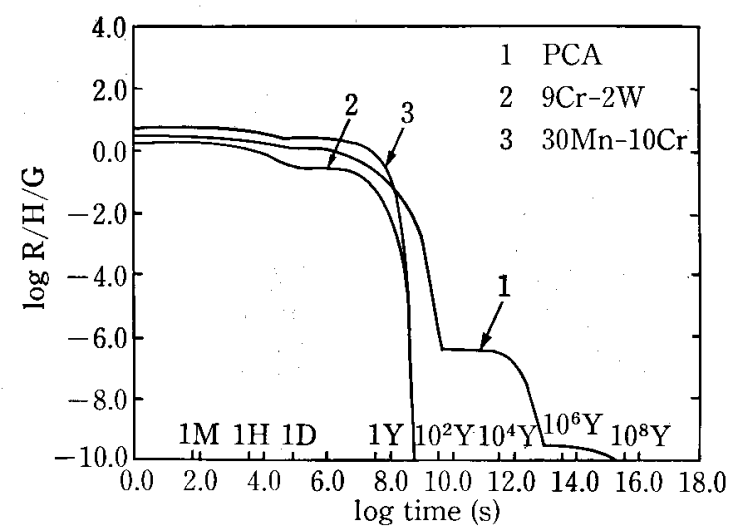

Fig. 3. Gamma-ray decay behaviors of PCA, Fe-9Cr-2W and $\mathrm{Fe}-30 \mathrm{Mn}-10 \mathrm{Cr}$ alloys. (Gamma-ray intensity after shutdown of operation of $1 \mathrm{MW} \cdot \mathrm{m}^{-2}$ for 10 years)

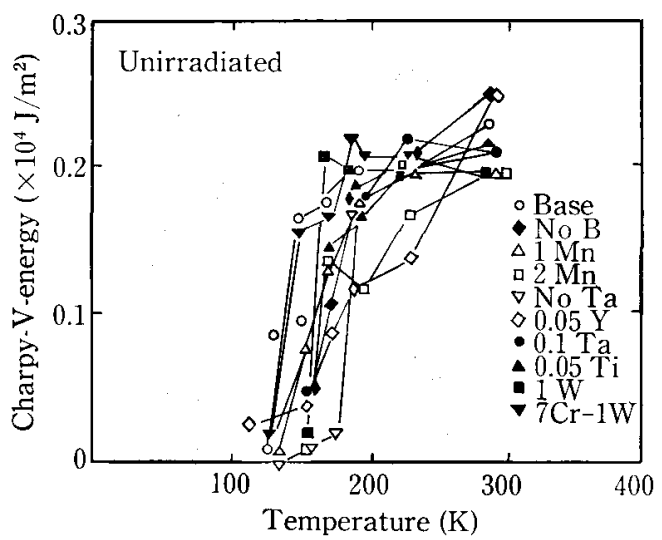

\section{Reduced Activation Ferritic Steels}

\subsection{Change in Toughness by Neutron Irradiation}

The decrease in toughness during thermal aging and neutron irradiation is the most serious problem for ferritic 7 to $12 \mathrm{Gr}-\mathrm{W}$ steel as well as 7 to $12 \mathrm{Gr}-\mathrm{Mo}$ steel. Fig. 4 shows the effect of neutron irradiation on Charpy impact energy of various $9 \mathrm{Cr}-2 \mathrm{~W}$ steels. ${ }^{12)}$ The change in DBTT (ductile-brittle transition temperature) of these steels is listed in Table 1 . The steel with base composition $(9 \mathrm{Gr}-2 \mathrm{~W}-0.5 \mathrm{Mn}-0.25 \mathrm{~V}-$ $0.05 \mathrm{Ta}-0.02 \mathrm{Ti}-0.03 \mathrm{~B}$ ) shows the best impact properties, the smallest change of DBTT and the lowest DBTT before and after irradiation. The combined addition of small amount of $\mathrm{Ti}$ and $\mathrm{B}$ was reported to be bencficial in making fine ferrite grain structure. ${ }^{12)}$ Rise in DBTT of ferritic steels caused by neutron irradiation is affected by $\mathrm{Gr}$ content. As shown in Fig. 5, the lowest DBTT is reached at around $9 \%$ Cr. ${ }^{13)}$

\subsection{High-temperature Strength and Toughness}

Creep rupture strength of 9 Cr steel is increased with increasing the alloying content of W (Fig. 6 $\left.{ }^{14}\right)$ ).

Table 1. DBT' $\mathrm{T}$ of irradiated and unirradiated $9 \mathrm{Cr}-$ $W$ ferritic steels and difference of DBTT $(\triangle T)$ between unirradiated and irradiated materials.

\begin{tabular}{|c|c|c|c|c|}
\hline \multirow{2}{*}{\multicolumn{2}{|c|}{ Specimens }} & \multicolumn{2}{|c|}{$\operatorname{DBTT}(\mathrm{K})$} & \multirow{3}{*}{$\frac{\Delta T(\mathrm{~K})}{10}$} \\
\hline & & \multirow{2}{*}{$\frac{\text { Unirradiated }}{148}$} & \multirow{2}{*}{$\frac{\text { Irradiated }}{158}$} & \\
\hline (1) & Base* & & & \\
\hline$\left(1^{\prime}\right)$ & No $B$ & 167 & $\therefore \quad 181$ & 14 \\
\hline & $1 \mathrm{Mn}$ & 160 & 193 & 33 \\
\hline (3) & $2 \mathrm{Mn}$ & 156 & 167 & 11 \\
\hline (4) & No Ta & 183 & 193 & 10 \\
\hline$\left(4^{\prime}\right)$ & $5.05 \mathrm{Y}$ & 183 & - & - \\
\hline (5) & $0.1 \mathrm{Ta}$ & 161 & 195 & 34 \\
\hline (6) & $0.05 \mathrm{Ti}$ & 159 & 213 & 54 \\
\hline (8) & $1 \mathrm{~W}$ & 161 & 172 & 11 \\
\hline$(8)$ & $7 \mathrm{Cr}-1 \mathrm{~W}$ & 143 & 173 & 30 \\
\hline $9 \mathrm{Cr}$ & $-1 \mathrm{Mo}$ & 169 & 203 & 34 \\
\hline
\end{tabular}

* Fe-9Cr-2W-0.5Mn-0.25V-0.05Ta-0.02Ti-0.003B.

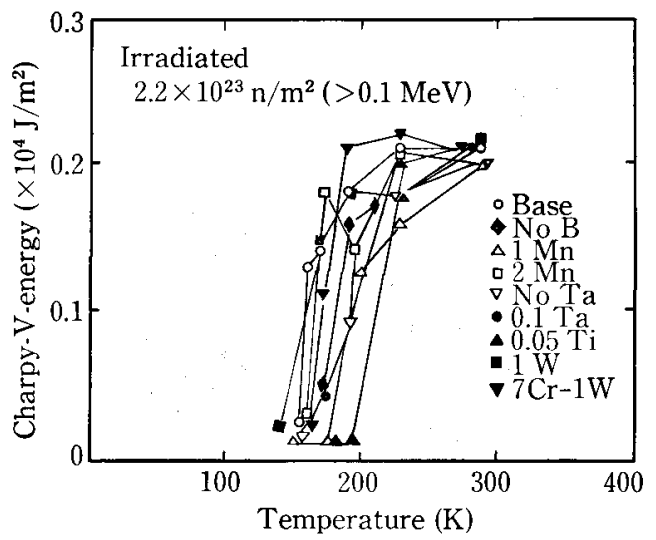

Fig. 4. Temperature dependence of the Charpy-V-notch absorbed energy of $9 \mathrm{Cr}-\mathrm{W}$ ferritic steels.

* See Table of footnote on p. 918 . 


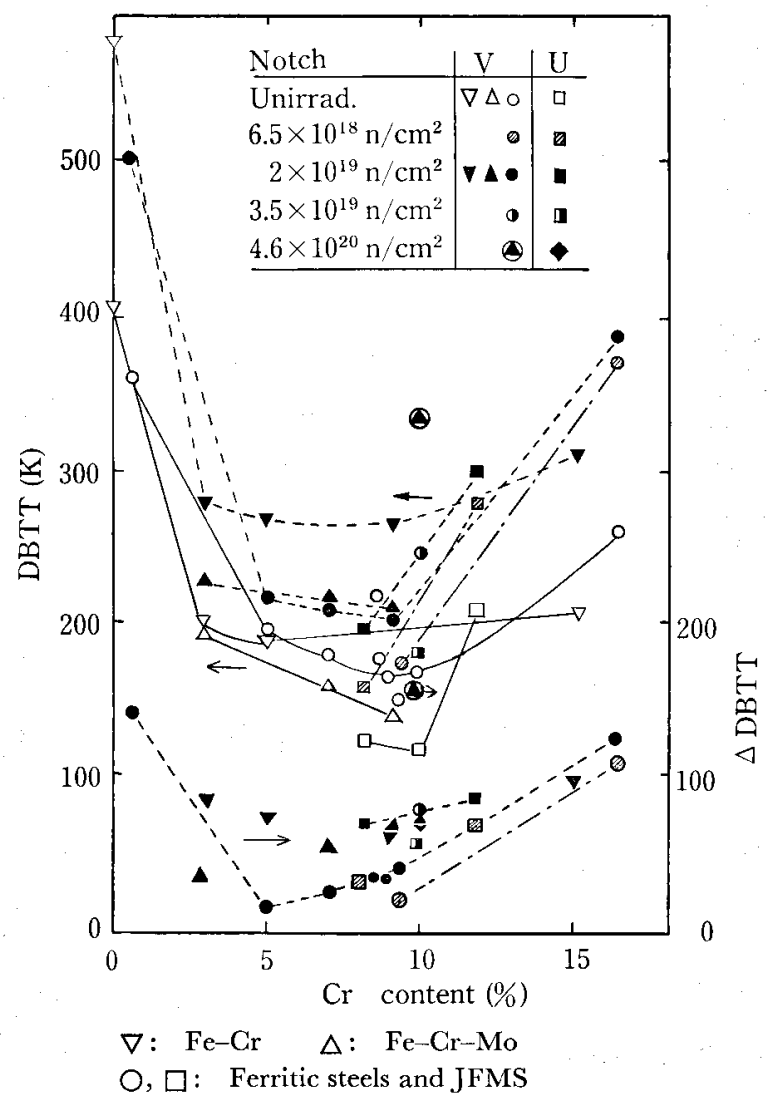

Fig. 5. Dependence of the DBTT of several ferritic steels on $\mathrm{Cr}$ content before and after neutron irradiation, in comparison with the previous data by $\mathrm{H}$. Kayano et al.

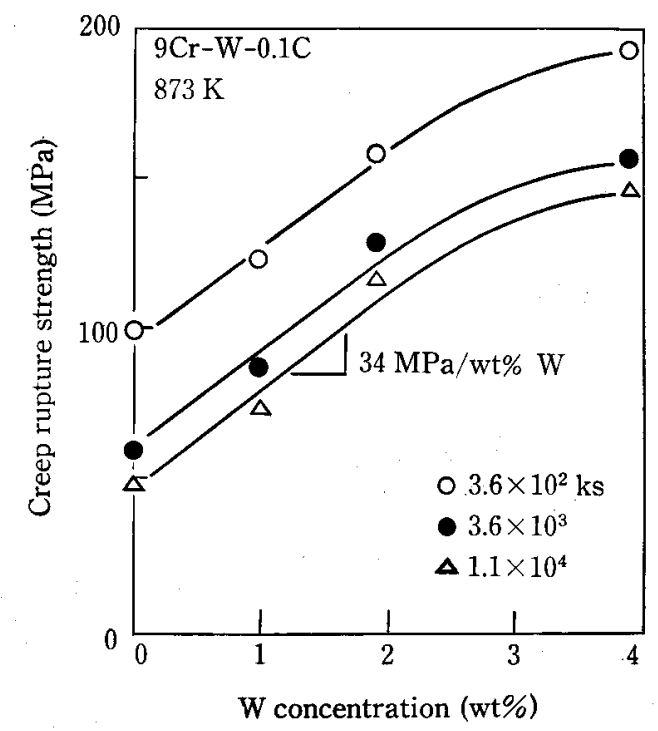

Fig. 6. Creep rupture strength of $9 \mathrm{Cr}-\mathrm{W}$ steels at $873 \mathrm{~K}$.

The addition of $\mathrm{W}$ is helpful in making martensite lath stable during creep at around $873 \mathrm{~K}$. Beneficial effect of $W$ to creep rupture strength is also shown in 2.25 to $3 \mathrm{Cr}$ steel. Fig. 7 shows the relation between applied stress and creep rupture time at $873 \mathrm{~K}$ for various Cr steels containing $2 \%$ of W. ${ }^{15}$ It is demonstrated that the creep rupture strength of 2.25 to $3 \mathrm{Cr}-2 \mathrm{~W}$ steel is superior to that of $2.25 \mathrm{Cr}-1 \mathrm{Mo}$ steel.

The addition of $\mathrm{W}$, however, decreases the tough-

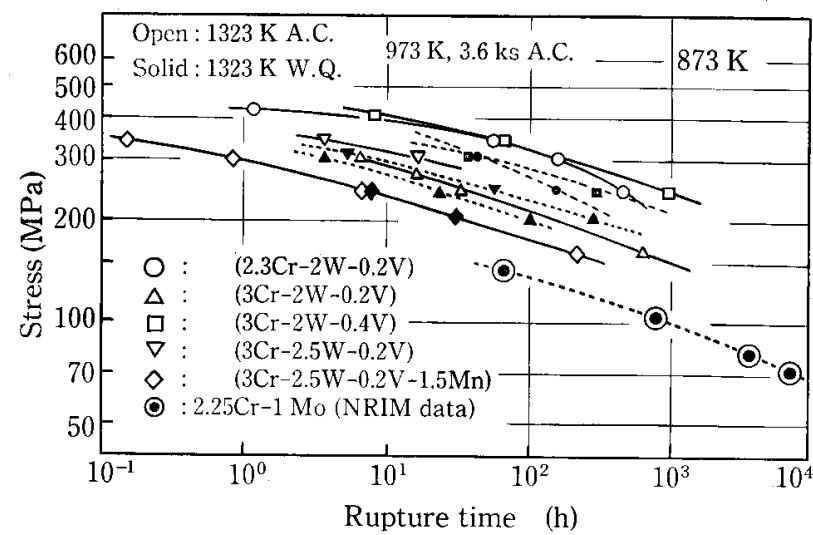

Fig. 7. Creep rupture strength of various $(2.25-3) \mathrm{Cr}-\mathrm{W}$ steels at $873 \mathrm{~K}$.

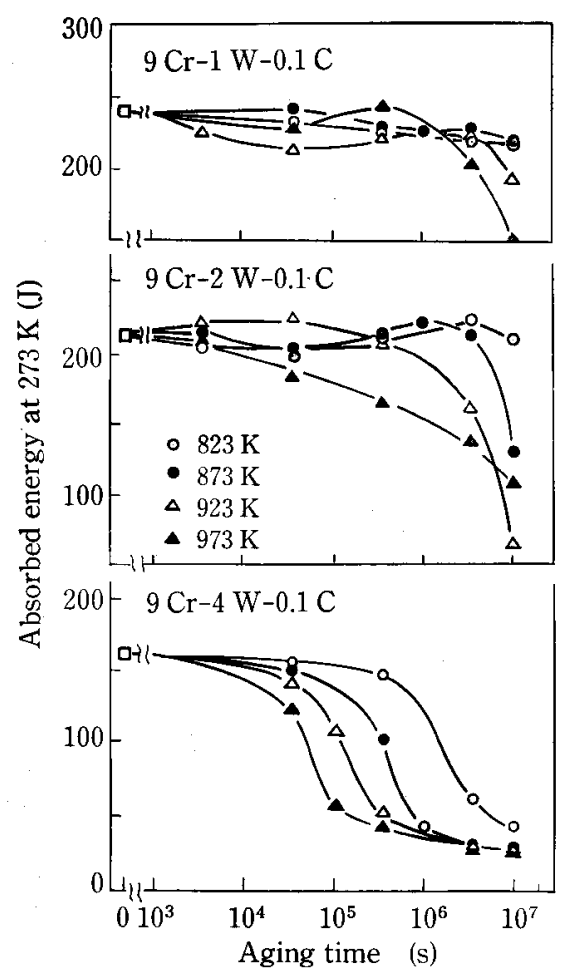

Fig. 8. Degradation curves of the absorbed energy at $273 \mathrm{~K}$ of the $9 \mathrm{Cr}-\mathrm{W}$ steels, as a function of aging time at $823,873,923$ and $973 \mathrm{~K}$.

ness of $9 \mathrm{Cr}$ steel. Fig. 8 indicates the change in absorbed energy at $273 \mathrm{~K}$ by impact test during aging. ${ }^{11)}$ The increase of $\mathrm{W}$ content decreases the absorbed energy more rapidly during aging. The decrease of toughness is mainly caused by precipitation of Laves phase, $\left.\mathrm{Fe}_{2} \mathrm{~W} .11,16\right)$ Fig. 9 shows the relation between creep rupture strength and DBTT of $9 \mathrm{Cr}-\mathrm{W}$ steel. ${ }^{17}$ ) The results suggest that the addition of $2 \%$ of $\mathrm{W}$ is preferable in both creep rupture strength and toughness.

A large possibility is suggested for improving creep rupture strength and toughness in $9 \mathrm{Cr}$ steel by substitution of $\mathrm{W}$ for Mo, although more extended studies, such as weldability and formability, are needed. A good resistance to void swelling in $9 \mathrm{Cr}-\mathrm{W}$ steels is also being confirmed. ${ }^{18)}$ The following alloy compositions 


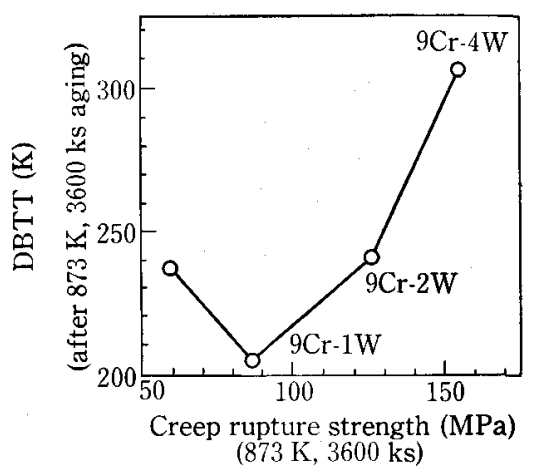

Fig. 9. The relation between DBTT and creep rupture strength of $9 \mathrm{Cr}-\mathrm{W}$ steels.

Table 2. Proposed materials as preferable reduced activation ferritic steels. (mass\%)

\begin{tabular}{ccrcccccc}
\hline Ref. & G & Si & Mn & Cr & W & V & Ta & N \\
\hline 19$)$ & 0.12 & 0.05 & 0.5 & 8.5 & 2.5 & 0.20 & 0.12 & 0.03 \\
$20)$ & 0.10 & 0.10 & 0.5 & 8.0 & 2.0 & 0.20 & 0.04 & \\
15) & 0.10 & $<0.10$ & 0.5 & 9.0 & 2.0 & 0.20 & 0.10 & 0.05 \\
\hline
\end{tabular}

$\begin{array}{lll}\text { Heat treatment : } & & \\ \text { Ref. 19) } & 1323 \mathrm{~K} \times 1.8 \mathrm{ks} & \text { Normalizing } \\ & 1023-1073 \mathrm{~K} \times 3.6 \mathrm{ks} & \text { Tempering } \\ \text { Ref. 20) } & 1313 \mathrm{~K} \times 1.8 \mathrm{ks} & \text { Normalizing } \\ & 1013 \mathrm{~K} \times 7.2 \mathrm{ks} & \text { Tempering } \\ \text { Ref. 15) } & 1323 \mathrm{~K} \times 1.8 \mathrm{ks} & \text { Normalizing } \\ & 1048 \mathrm{~K} \times 3.6 \mathrm{ks} & \text { Tempering }\end{array}$

are recommended as preferable reduced activation ferritic steels. ${ }^{15,19,20)}$ (Table 2)

\section{Reduced Activation Austenitic Steels}

\section{1. $\quad$ o Phase Formation}

In $\mathrm{Fe}-\mathrm{Cr}-\mathrm{Mn}$ alloy, $\sigma$ phase formation is one of the serious problems and markedly affected by $\mathrm{Mn}$ content. Increase in $\mathrm{Mn}$ content promotes the $\sigma$ phase formation in the temperature range from 773 to $973 \mathrm{~K}$ as shown in Fig. 10. ${ }^{21)}$ It is noted that this effect of $\mathrm{Mn}$ is quite different from the effect of $\mathrm{Ni}$ which prevents $\sigma$ phase formation. Chromium is also a detrimental element in forming $\sigma$ phase. As $\mathrm{Cr}$ content increases, $\sigma$ phase forms more easily (Fig. 11).22)

Effect of $\mathrm{Mn}$ and $\mathrm{Cr}$ contents on $\sigma$ phase formation is summarized in the $\mathrm{Fe}-\mathrm{Cr}-\mathrm{Mn}$ ternary system at $923 \mathrm{~K}$ obtained by Burgess and Forgeng ${ }^{23)}$ (Fig. 1222). In the present case, all data were obtained from aging for $3.6 \times 10^{3} \mathrm{ks}$ after cold rolling. It is noted that the region of $\sigma$ phase formation spreads more widely than that indicated in the phase diagram. In this figure, the predicted $\gamma /(\gamma+\sigma)$ boundary ( $M d$ line) is shown, which is evaluated using the $d$-electron concept by Yukawa et al. ${ }^{24)}$

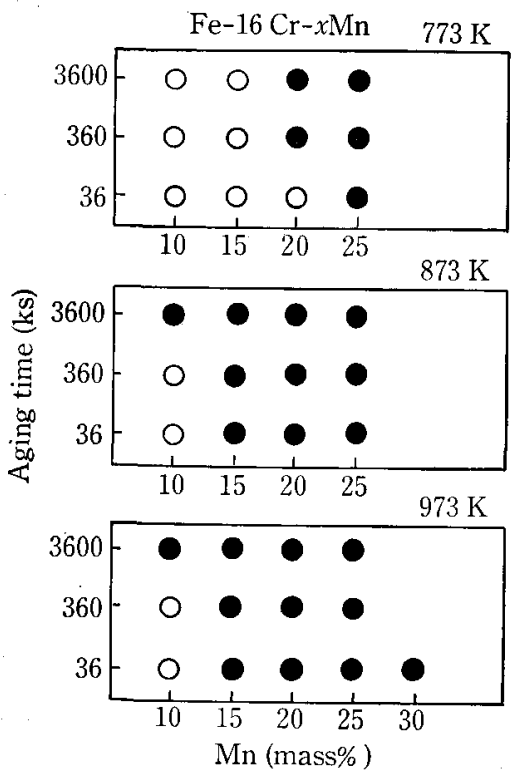

$O:$ Non $\sigma$ phase $\quad \sigma$ phase formation

Fig. 10. Effect of manganese content, aging time and aging temperature on the formation of $\sigma$ phase in $\mathrm{Fe}-16 \% \mathrm{Cr}-\mathrm{Mn}$ alloys.

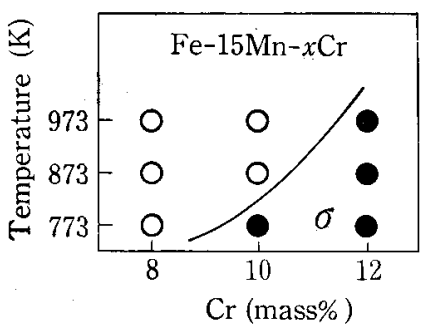

$\bigcirc:$ Non $\sigma$ phase $\quad 0$ phase formation

Fig. 11. Effect of $\mathrm{Cr}$ content and aging temperature on $\sigma$ phase formation in $\mathrm{Fe}-15 \mathrm{Mn}-\mathrm{Cr}$ alloys after solution treatment followed by $50 \%$ cold work.

The temperature dependence of $\overline{M d}{ }^{*}$ for the $\gamma / \gamma+\sigma$ phase boundaries in various ternary alloys is also shown in Fig. 13,25) and they expressed its temperature dependence as follows:

$$
\text { Critical } \overline{M d}=6.25 \times 10^{-5} T+0.834 \text {. }
$$

They also confirmed that the stable $\gamma$ phase field can be more accurately presented by the $\overline{B o^{*}} v s . \overline{M d}$ diagram in $\mathrm{Fe}-\mathrm{Cr}-\mathrm{Mn}-\mathrm{Ni}$ alloys as shown in Fig. $14,{ }^{25)}$ than the Schaeffler diagram. ${ }^{26)}$

$\mathrm{C}, \mathrm{N}$ and $\mathrm{Ni}$ are well known to be very beneficial elements for preventing $\sigma$ phase formation in stainless steels. A similar effect of these elements was also found in the present alloys. Fig. 15 shows the effect of $\mathcal{N} i_{\mathrm{eq}}^{*}$ value and aging temperature on $\sigma$ phase formation in $\mathrm{Fe}-12 \mathrm{Cr}-15 \mathrm{Mn}-\mathrm{C}-\mathrm{N}-\mathrm{Ni}$ alloys. ${ }^{22)}$ It is evident that $\sigma$ phase formation is prevented in the

* $M d$ is a parameter relating to the $d$-orbital level of alloying transition metal. Bo is a parameter relating to the covalent bond strength between atoms. $\overline{M d}$ and $\overline{B o}$ are the average values of $M d$ and $B o$ of alloy, defined by

$$
\overline{M d}=\sum X_{i}(M d)_{i}, \overline{B o}=\sum X_{i}(B o)_{i}, \quad \text { where, } \quad X_{i} \text { : the atomic fraction of component } i \text { in the alloy }
$$

Refer to Ref. 24) in details.

$(M d)_{i},(B o)_{i}$ : the $M d$ and $B o$ values for component $i$, respectively. 


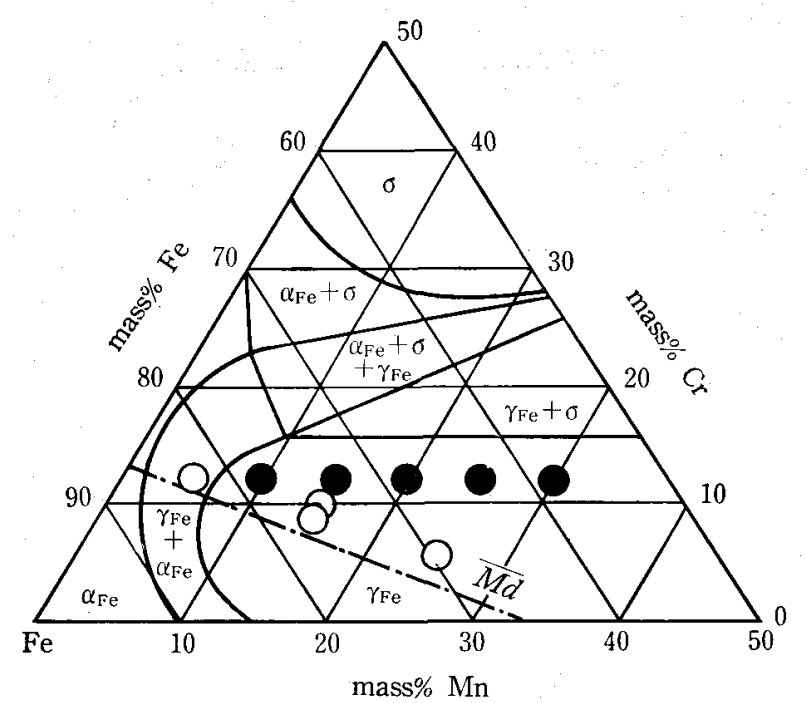

0 : Non $\sigma$ phase formation

- : $\sigma$ phase formation

Fig. 12. Phase diagram of the Fe-Cr-Mn ternary system at $923 \mathrm{~K}$ and Ergang and the region of $\sigma$ phase formation determined by Y. Okazaki et al..$^{22}$

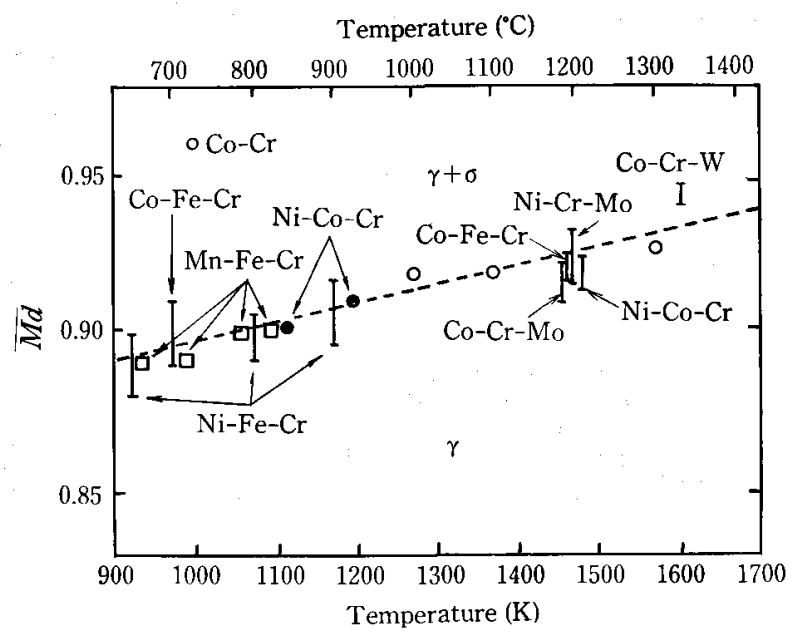

Fig. 13. Temperature dependence of critical $\overline{M d}$ for the $\sigma$ phase in various alloys.

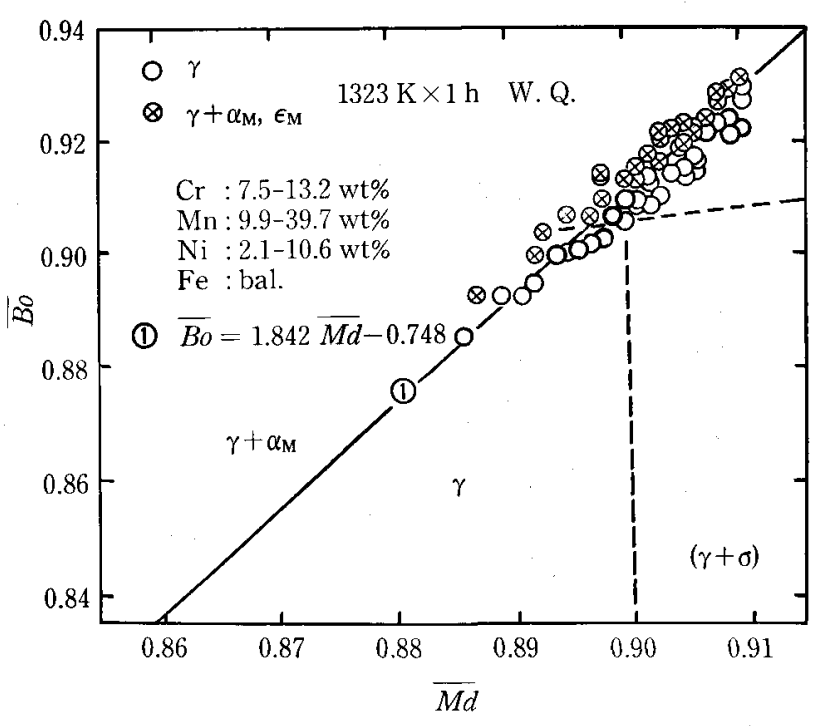

Fig. 14. $\gamma$ phase field of $\mathrm{Fe}-\mathrm{Cr}-\mathrm{Mn}-\mathrm{Ni}$ alloys shown in $\overline{B o}-$ $\overline{M d}$ diagram.

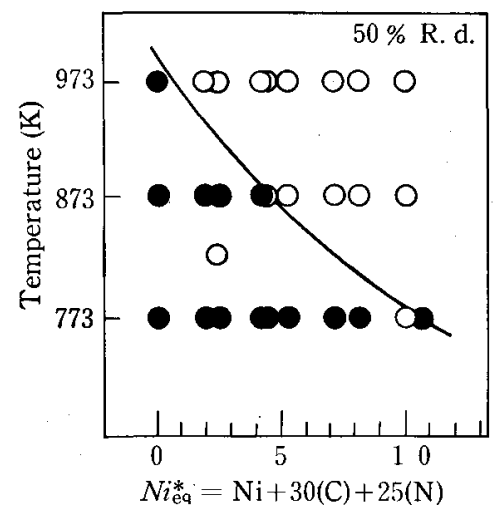

0 : Non $\sigma$ phase formation

0 : $\sigma$ phase formation

Fig. 15. Effect of $\mathrm{Ni}^{*}$ equivalent and aging temperature on $\sigma$ phase formation in $\mathrm{Fe}-\mathrm{Cr}-\mathrm{Mn}-\mathrm{C}-\mathrm{N}-\mathrm{Ni}$ alloys.

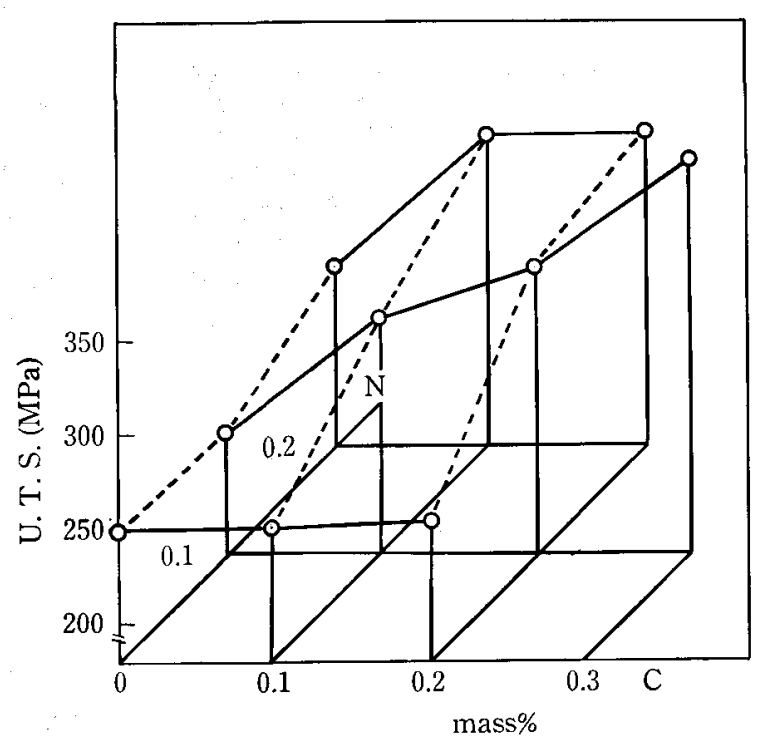

Fig. 16. Effect of $\mathrm{C}$ and $\mathrm{N}$ on the ultimate tensile strength of $\mathrm{Fe}-12 \mathrm{Cr}-15 \mathrm{Mn}-\mathrm{C}-\mathrm{N}$ alloys.

temperature range between 773 and $973 \mathrm{~K}$ when the $\mathcal{N i}_{\text {eq }}^{*}$ value is greater than 10 . It is mentioned that the addition of $0.2 \% \mathrm{C}$ and $0.2 \% \mathrm{~N}$ is required to prevent $\sigma$ phase formation in $\mathrm{Ni}$-free $\mathrm{Fe}-12 \mathrm{Cr}-15$ Mn alloy.

\subsection{High-temperature Strength}

The effect of $\mathrm{C}$ and $\mathrm{N}$ on high-temperature tensile strength of $12 \mathrm{Gr}-15 \mathrm{Mn}$ steel at $873 \mathrm{~K}$ is shown in Fig. 16. 27) $\mathrm{C}$ and $\mathrm{N}$ are considered to have similar effects on this property. It seems that the combined addition of $\mathrm{C}$ and $\mathrm{N}$ is very beneficial in increasing high-temperature strength. Fig. 17 shows the change in tensile properties (tensile strength, $0.2 \%$ proof strength and total elongation) with the amounts of $\mathrm{C}+\mathrm{N}$ in $12 \mathrm{Cr}-15 \mathrm{Mn}$ steel. ${ }^{28)}$ It indicates that comparable tensile strength and elongation with JPGA is obtained when the steel contains $0.4 \%(\mathrm{C}+\mathrm{N})$. It should be noted that the $12 \mathrm{Cr}-15 \mathrm{Mn}-0.2 \mathrm{C}-0.2 \mathrm{~N}$ steel has entircly austenitic structure and does not form $\sigma$ phase. 


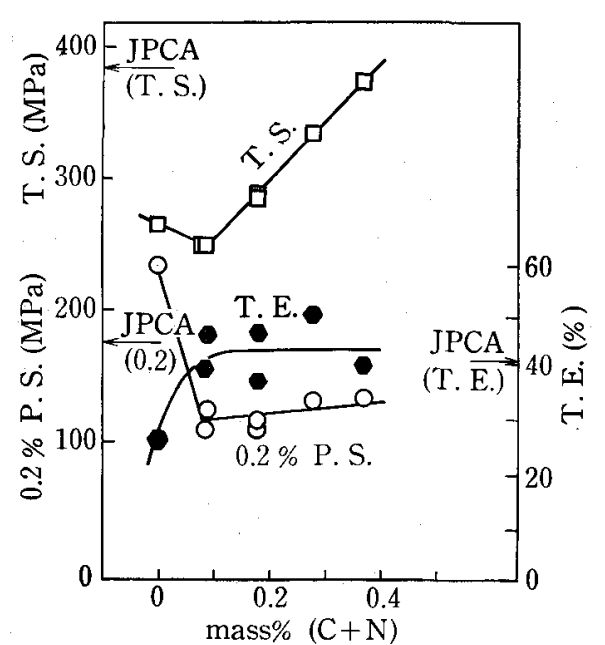

Fig. 17. Tensile strength, $0.2 \%$ proof stress and total elongation of $\mathrm{Fe}-12 \mathrm{Cr}-15 \mathrm{Mn}-\mathrm{C}-\mathrm{N}$ alloy tested at $873 \mathrm{~K}$ after solution-treatment and aging at $873 \mathrm{~K}$ for $36 \mathrm{ks}$ as a function of $\mathrm{C}$ plus $\mathrm{N}$ (mass \%).

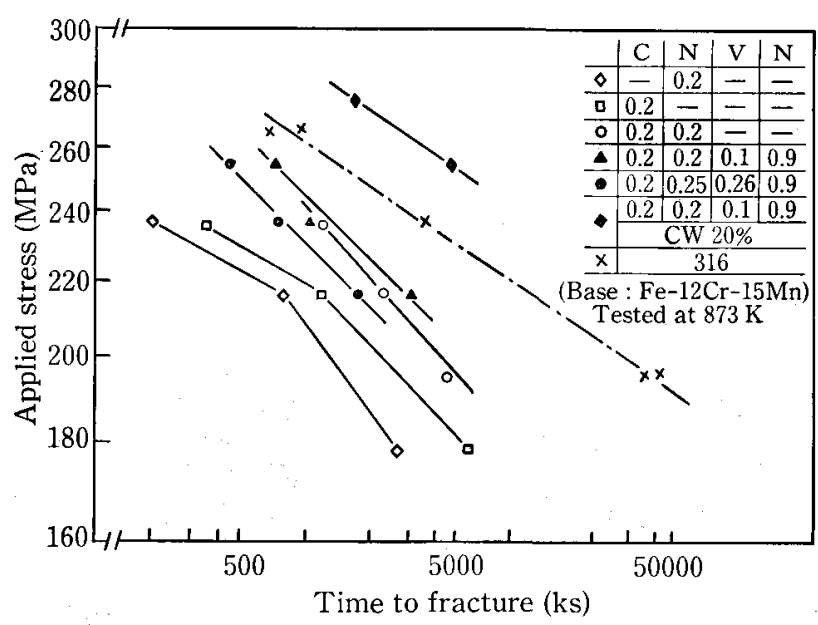

Fig. 18. Relation between applied stress and time to fracture of various $\mathrm{Fe}-12 \mathrm{Cr}-15 \mathrm{Mn}$ alloys in creep test at $873 \mathrm{~K}$.

Improvement effect of combined addition of $\mathrm{C}$ and $\mathrm{N}$ was also shown on creep rupture strength in Fig. 18 indicating the relation between applied stress and time to fracture. ${ }^{27)}$ Effect of small amount of $\mathrm{V}$ is also demonstrated in this figure. Addition of $0.1 \% \mathrm{~V}$ slightly improves creep rupture strength but addition of $0.2 \% \mathrm{~V}$ decreases it. Cold work (about $20 \%$ ) is found to be pronouncedly effective in increasing creep rupture strength, as shown in Fig. 18. The strength was reported to be attributable to finely precipitated carbides in the grain interior along slip lines caused by cold work. ${ }^{27)}$

The creep rupture strength is markedly improved by alloying with W. Fig. 19 indicates the effect of $\mathrm{W}$ on time to fracture and minimum creep rate of $12 \mathrm{Cr}-15 \mathrm{Mn}$ steel at $873 \mathrm{~K}$ under the applied stress of $216 \mathrm{MPa}$. Minimum creep rate is decreased and time to fracture increased with addition of $2 \%$ of W. Fig. 20 shows the comparison of creep rupture strength of $12 \mathrm{Cr}-18 \mathrm{Mn}-2 \mathrm{~W}$ steel with that of austenitic $\mathrm{Cr}-\mathrm{Ni}$ stainless steels. ${ }^{15}$ ) It is understood

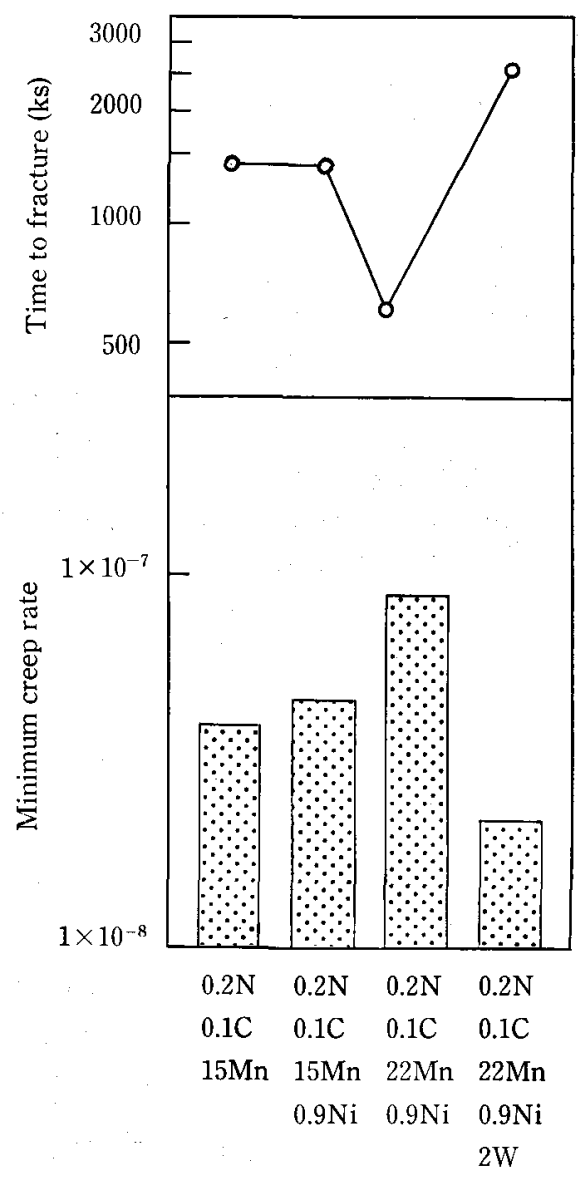

Fig. 19. Effect of $\mathrm{Mn}$ and $\mathrm{W}$ on time to fracture and minimum creep rate of $12 \mathrm{Cr}-15 \mathrm{Mn}$ steel.

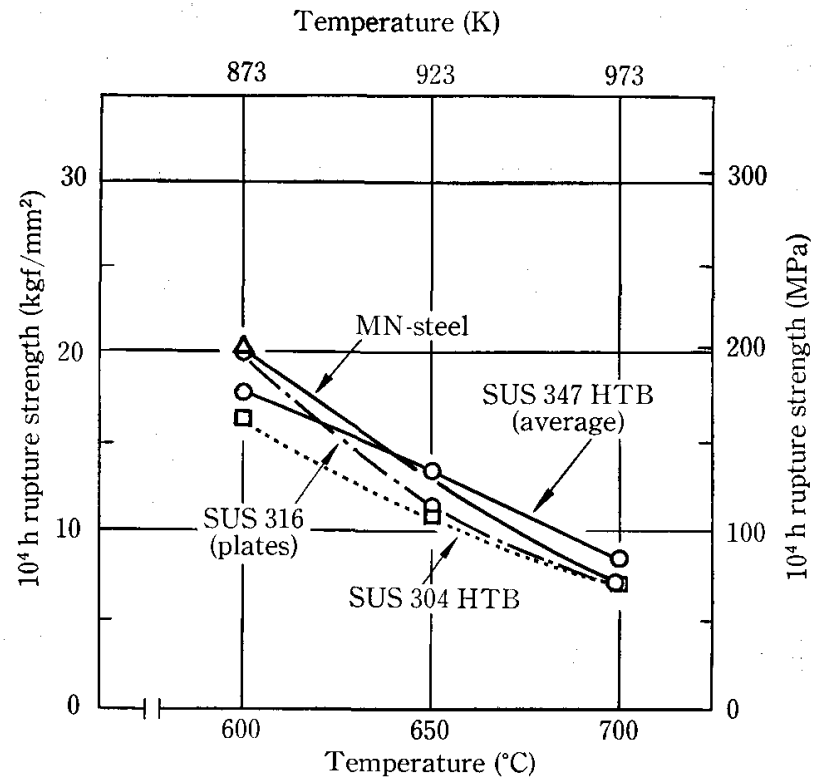

Fig. 20. Comparison of creep rupture strength for $10^{4} \mathrm{~h}$ of $12 \mathrm{Cr}-18 \mathrm{Mn}-2 \mathrm{~W}$ steel (MN-steel) with that of austenitic $\mathrm{Cr}-\mathrm{Ni}$ stainless steels.

that creep rupture strength of these steels are comparable.

As mentioned above, in the development of austenitic high $\mathrm{Mn}-\mathrm{Cr}$ steel, the utilization of $\mathrm{C}$ and $\mathrm{N}$ is necessary for the prevention of $\sigma$ phase formation and the increase of high-temperature strength. The 
alloying of $\mathrm{W}$ is also helpful in improving creep rupture strength.

\subsection{Void Swelling}

Much efforts have been dedicated to make clear the mechanism and fission-fusion correlation of void swelling in pure metals, simple alloys and engineering meratials in Japan as well as in U.S.A. and Europe. ${ }^{3-6)} \Lambda$ s for reduced activation ferrous materials, however, experimental results of void swelling especially by neutron irradiation are relatively few in Japan. The void swelling characteristics of these materials are now investigated by using FFTF/MOTA (Fast Flux Test Facility, Materials Open Test Assembly) in Pacific Northwest Laboratory, U.S.A. under the MONBUSYO-DOE Collaboration. ${ }^{29}$

Generally, void swelling of ferritic steels is difficult to occur compared with austenitic steels as shown in Fig. 21.10) In this section, some results of void swell-

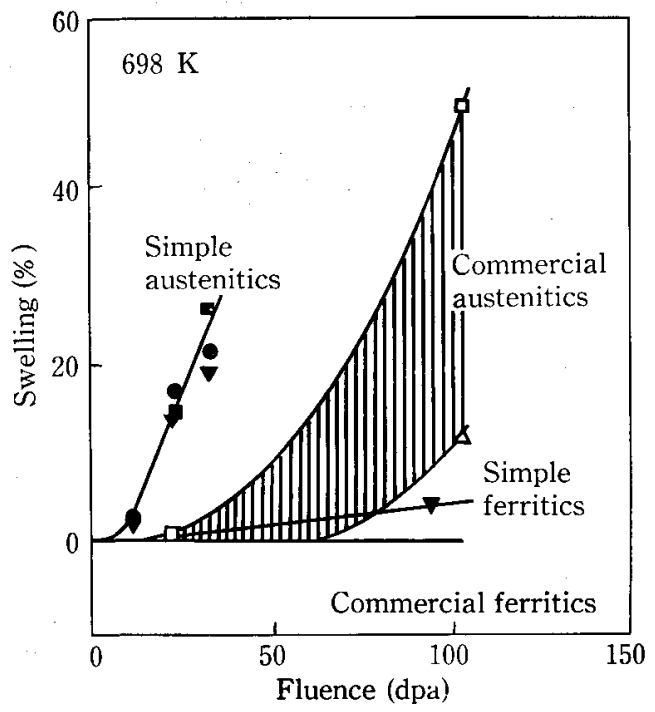

Fig. 21. Comparison of the swelling behavior of austenitic with ferritic steels.

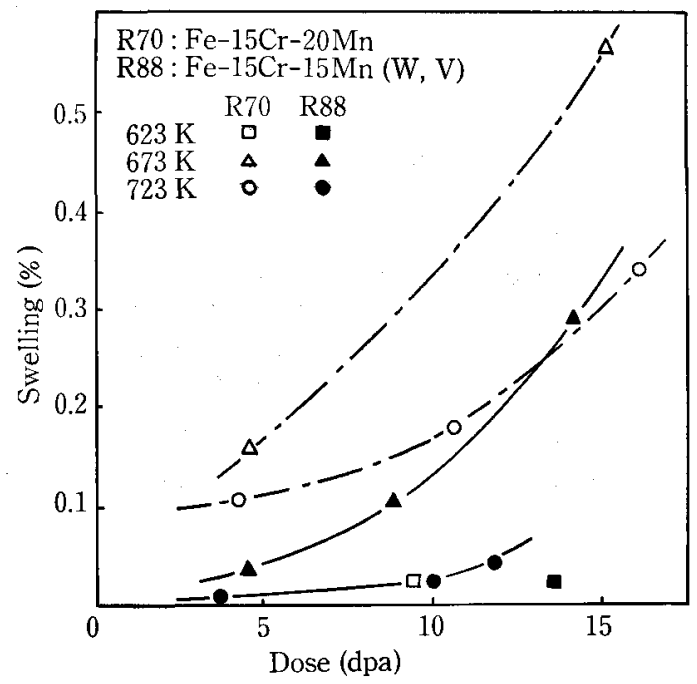

Fig. 22. Dose dependence of swelling for $\mathrm{Fe}-15 \mathrm{Cr}-20 \mathrm{Mn}$ and $\mathrm{Fe}-15 \mathrm{Cr}-15 \mathrm{Mn}(\mathrm{W}, \mathrm{V})$ alloys at various temperatures. ing of austenitic $\mathrm{Fe}-\mathrm{Mn}-\mathrm{Cr}$ alloys are referred comparing with that of austenitic $\mathrm{Fe}-\mathrm{Ni}-\mathrm{Cr}$ alloys, which include study in U.S.A.

In $\mathrm{Fe}-\mathrm{Mn}-\mathrm{Cr}$ alloys, voids form in significant numbers only in the temperature range 623 to $723 \mathrm{~K}$ and are at lower densities than observed in $\mathrm{Fe}-\mathrm{Ni}-\mathrm{Cr}$ alloy as demonstrated in Figs. 22 and 23,0) respectively. In these case, void formation was introduced by electron irradiation using high voltage electron microscope. It is found that void swelling by electron irradiation decreases with addition of $\mathrm{W}$ and $\mathrm{V}$ (Fig. 24). ${ }^{31}$ ) Increase amount of $\mathrm{Mn}$ is also effective in decreasing neutron-induced swelling of $\mathrm{Fe}-\mathrm{Mn}$ and Fe-Cr-Mn alloys (Fig. 25). ${ }^{32}$ ) In the neutron-induced swelling, the beneficial effect of $\mathrm{Mn}$ and $\mathrm{Ni}$ on decrease of swelling is seemed to be comparable as shown in Fig. 26. ${ }^{32}$ Void swelling increases with increasing irradiation fluence and the swelling rate is less than $1 \% / \mathrm{dpa}$ in $\mathrm{Fe}-\mathrm{Mn}$ and $\mathrm{Fe}-\mathrm{Cr}-\mathrm{Mn}$ alloys (Fig. 27). ${ }^{32)}$ A commercial high $\mathrm{Mn}$ steel, AMCR 0033 shows much lower swelling than simple Fe-Mn and $\mathrm{Fe}-\mathrm{Cr}-\mathrm{Mn}$ alloys as indicated in Fig. 27. AMCR 0033 contains $\mathrm{C}$ and $\mathrm{N}$ which form carbides and nitrides in the steel. These dispersed carbides and

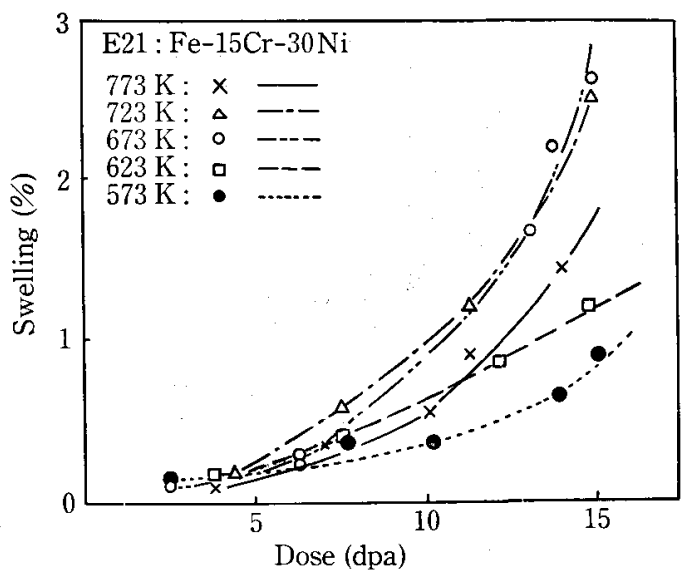

Fig. 23. Dose dependence of swelling for the $\mathrm{Fe}-15 \mathrm{Cr}-30 \mathrm{Ni}$ alloy at various temperatures.

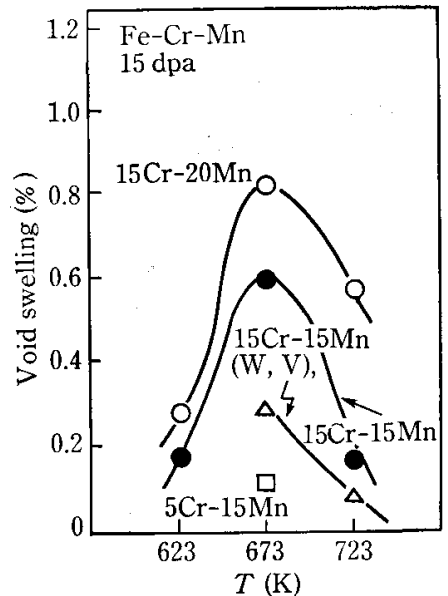

Fig. 24. Void swelling as a function of irradiation temperature for $\mathrm{Fe}-\mathrm{Cr}-\mathrm{Mn}$ alloys after irradiation to 15 dpa. 


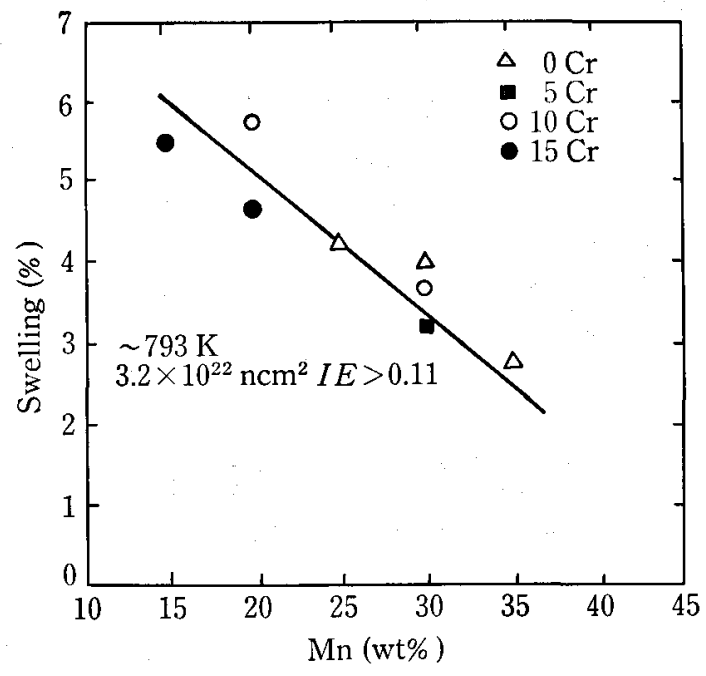

Fig. 25. Neutron-induced swelling of $\mathbf{F e}-\mathrm{Mn}$ and $\mathrm{Fe}-\mathrm{Cr}-$ Mn alloys in FFTF at $793 \mathrm{~K}$ and 14 dpa as determined by immersion dencity measurements.

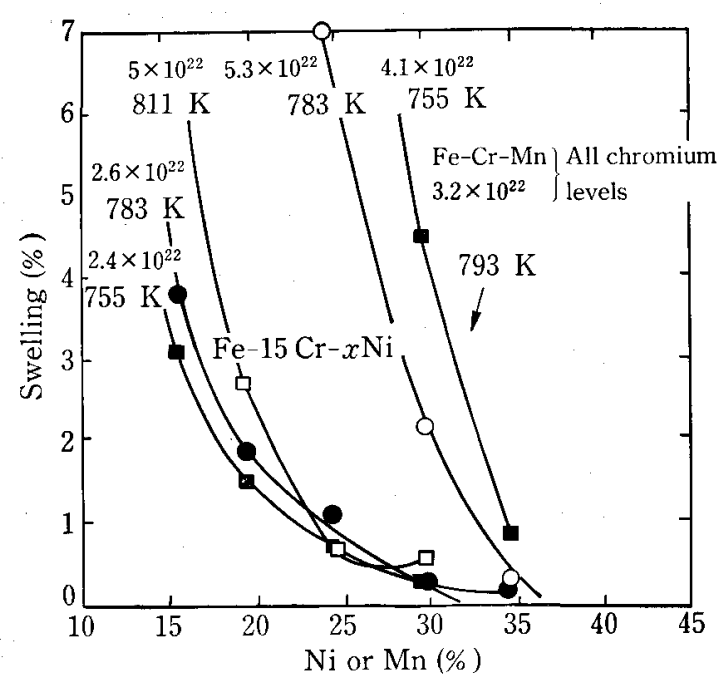

Fig. 26. Comparison of swelling of $\mathrm{Fe}-\mathrm{Cr}-\mathrm{Ni}$ and $\mathrm{Fe}-\mathrm{Cr}-$ $\mathrm{Mn}$ alloys at comparable irradiation conditions.

nitrides increase the void nucleation site, resulting in the decrease of void swelling as a whole. Cold work also increases the void nucleation site and decreases void swelling. Decrease of void swelling by cold work had previously obtained in type 316 stainless steel and many austenitic $\mathrm{Fe}-\mathrm{Ni}-\mathrm{Gr}$ alloys. ${ }^{33}$ )

\section{Summary}

The outline of research and development of reduced activation ferrous materials, today in Japan, is reviewed. Low or reduced activation materials are used for the first wall material of fusion reactor. Consept of low or reduced activation materials is closely related to the waste management and reactor safety. True low activation materials are considered to be $\mathbf{S i}$, $\mathrm{C}$ and $\mathrm{SiC}$. In near-term construction of fusion reactor or fusion reaction facility, however, the utilization of reduced activation ferrous materials is seemed to be the most practical way. It is required for these materials that the land disposal limit, 10GFR61 limit,

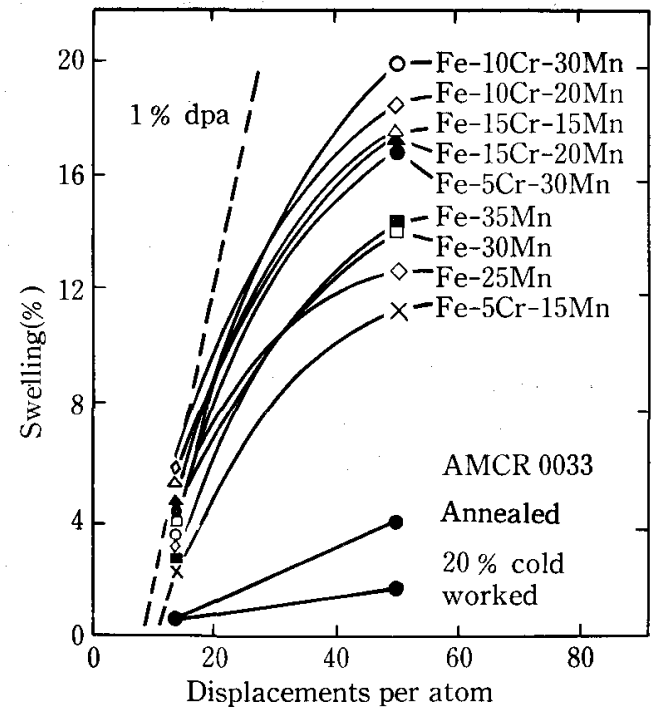

Fig. 27. Swelling of simple $\mathrm{Fe}-\mathrm{Cr}-\mathrm{Mn}$ alloys at $723 \mathrm{~K}$ in FFTF-MOTA. The swelling of commercial alloy AMCR 0033 is also shown. (AMCR 0033: $10 \mathrm{Cr}$ $18 \mathrm{Mn}-0.7 \mathrm{Ni}-0.6 \mathrm{Si}-0.2 \mathrm{C}-0.06 \mathrm{~N}$ )

must be satisfied at least. Ferritic $9 \mathrm{Cr}-\mathrm{W}$ steels and austenitic $\mathrm{Mn}-\mathrm{Cr}$ steels are now being developed in Japan, which satisfy this limit. In this review, the characteristic features of these materials is presented. However more detailed study and many engineering data are required in order to develop and use these materials as the practical structure. In Japan, data bank system for engineering materials used for fusion reactor is now being developed. ${ }^{34)}$

\section{REFERENCES}

1) R. L. Klueh, D. S. Gelles, M. Okada and N. H. Packan: "Reduced Activation Materials for Fusion Reactors", ASTM. Spec. Tech. Publ. No. 1047, ASTM, Philadelphia, PA, (1990), 1.

2) "Effect of Radiation on Reduced Activation Ferrous Materials", Research Report of the Grant-in-Aid for Fusion Research of the Ministry of Education, Science and Culture of Japan, No. 63050024, Y. Hosoi, ed., (1989).

3) Proc. of First Int. Conf. on Fusion Reactor Materials, Tokyo, Elsevier Sci. Publ. B. V., Amsterdam, (1984).

4) Proc. of Second Int. Conf. on Fusion Reactor Materials, Chicago, Elsevier Sci. Publ. B. V., Amsterdam, (1986).

5) Proc. of Third Int. Conf, on Fusion Reactor Materials, Karlsruhe, Elsevier Sci. Publ. B. V., Amsterdam, (1987).

6) Proc. of Fourth Int. Conf. on Fusion Reactor Materials, Kyoto, Elsevier Sci. Publ. B. V., Amsterdam, (1989), in press.

7) T. Noda, H. Araki, F. Abe and M. Okada: Trans, Nat. Res. Inst. Met., 30 (1988), 185.

8) F. M. Mann: HEDL-TIME Rep. No. 83-27, (1983).

9) F. M. Mann: Fusion Technol., 6 (1984), 273.

10) for example, T. Lechtenberg: J. Nucl. Mater., 133 \& 134 (1985), 149.

11) M. Okada, T. Noda and F. Abe: J. Nucl. Mater., 169 (1989), 249.

12) H. Kayano, A. Kimura, M. Narui, Y. Sasaki, Y. Suzuki and S. Ohta: J. Nucl. Mater., 155-157 (1988), 978.

13) H. Yoshida, K. Miyata, M. Narui and H. Kayano: J. Nucl. Mater., 169 (1989), 217.

14) M. Okada: "Effect of Radiation on Reduced Activation 
Ferrous Materials", Research Report of the Grant-in-Aid for Fusion Research of the Ministry of Education, Science and Culture of Japan, No. 63050024, Y. Hosoi, ed., (1989), 150.

15) K. Asakura: "Effect of Radiation on Reduced Activation Ferrous Materials", Research Report of the Grant-in-Aid for Fusion Rescarch of the Ministry of Education, Science and Gulture of Japan, No. 63050024, Y. Hosoi, ed., (1989), 135.

16) S. Kunimitsu, Y. You, N. Kasuya, Y. Sasaki and Y. Hosoi: Proc. of Fourth Int. Conf. on Fusion Reactor Materials, Kyoto, Eilsevier Sci. Publ. B. V., Amsterdam, (1989), in press.

17) M. Okada and F. Abe, National Research Inst. for Metals, Japan, (March, 1988): Private communication.

18) A. Koyama and Y. Kono: "Effect of Radiation on Reduced Activation Ferrous Materials", Research Report of the Grant-in-Aid for Fusion Research of the Ministry of Education, Science and Culture of Japan, No. 63050024, Y. Hosoi, ed., (1989), 91.

19) T. Fujita: "Effect of Radiation on Reduced Activation Ferrous Materials", Research Report of the Grant-in-Aid for Fusion Research of the Ministry of Education, Science and Culture of Japan, No. 63050024, Y. Hosoi, ed., (1989), 45.

20) M. Tamura, H. Hayakawa, M. Tanimura, A. Hishinuma and T. Kondo: J. Nucl. Mater., 141-143 (1986), 1067.

21) Y. Okazaki, M. Mochizuki, K. Miyahara and Y. Hosoi: ASTM Spec. Tech. Publ. No. 1047, ASTM, Philadelphia, PA, (1990), 80.

22) Y. Okazaki, K. Miyahara, Y. Hosoi, M. Tanino and H. Komatsu: J. Jpn. Inst. Met., 53 (1989), 512.
23) C. O. Burgess and W. D. Forgeng: Trans. Am. Inst. Min. Metall. Pet. Eng., 131 (1938), 277.

24) M. Morinaga, N. Yukawa and H. Adachi: Tetsu-to-Hagané, 71 (1985) 19.

25) N. Yukawa, M. Morinaga, K. Nishiyama, Y. Matsumoto, Y. Murata and H. Ezaki: ASTM Spec. Tech. Publ. No. 1047, ASTM, Philadelphia, PA, (1990), 30.

26) A. L. Schaeffler: Metal Prog., 56 (1949), 680.

27) Y. Hosoi: Proc. of Fourth Int. Conf. on Fusion Reactor Materials, Kyoto, Elsevier Sci. Publ. B. V., Amsterdam, (1989), in press.

28) Y. Okazaki, N. Wade, K. Miyahara and Y. Hosoi: J.Jpn. Inst. Met., 53 (1989), 522.

29) Annual Progress Report for Monbusho-DOE Collaboration in Fundamental Studies of Irradiation Effects in Fusion Materials Utilizing Fission Reactors, (1988).

30) H. Takahashi, F. A. Garner, H. Itoh, B. Hu and S. Ohnuki: ASTM Spec. Tech. Publ. No. 955, ASTM, Philadelphia, PA, (1987), 268.

31) F. Wan H. Takahashi, S. Ohnuki and R. Nagasaki: $J$. Nucl. Mater, 155-157 (1988), 770.

32) F. A. Garner, H. R. Brager, D. S. Gelles and J. M. McGarthy: J. Nucl. Mater., 148 (1987), 294.

33) J. L. Straalsund, H. R. Brager and J. Holmes: RadiationInduced Void in Metals, ed. by J. W. Corbett and L. C. Ianniello, USAEC, (1972), 142.

34) S. Iwata: "Effect of Radiation on Reduced Activation Ferrous Materials", Research Report of the Grant-in-Aid for Fusion Research of the Ministry of Education, Science and Culture of Japan, No. 63050024, Y. Hosoi, ed., (1989), 86. 